\title{
UK public will choose which scientific puzzle to investigate for 2014 Longitude Prize
}

This News story (BMJ 2014;348:g3417, doi:10.1136/bmj.g3417) incorrectly says that the Horizon programme is due to be screened on 25 May, when it is, in fact, due to air on 22 May.
Cite this as: BMJ 2014;348:g3456

๑ BMJ Publishing Group Ltd 2014 